\title{
Socioeconomic differences in cancer survival among Swedish children
}

\author{
Hanna Mogensen ${ }^{\star}, 1$, Karin Modig ${ }^{1}$, Giorgio Tettamanti ${ }^{1}$, Mats Talbäck ${ }^{1}$ and Maria Feychting ${ }^{1}$ \\ ${ }^{1}$ Unit of Epidemiology, Institute of Environmental Medicine, Karolinska Institutet, PO Box 210, Stockholm SE-171 77, Sweden
}

\begin{abstract}
Background: Earlier evidence, also from high-income countries, suggests that parental socioeconomic status might influence survival from childhood cancer. This nationwide cohort study aimed to determine whether survival from childhood cancer in Sweden varies according to parental educational level and household income at the time of the child's diagnosis.
\end{abstract}

\begin{abstract}
Methods: All children aged 1-14 years with a first primary diagnosis of cancer during 1991 to 2010 identified from the Swedish Cancer Register were included. Using Cox regression, the effects of parental educational level and household income on childhood cancer survival were estimated.
\end{abstract}

\begin{abstract}
Results: For all diagnoses combined $(n=4700)$, children of parents with compulsory or less education and upper-secondary education had poorer survival compared with children with parents who had the highest educational level, adjusted hazard ratios 1.28 (95\% confidence interval 1.03-1.59) and 1.17 (1.00-1.38). Results for leukaemia and nervous system tumours showed a similar pattern but were not statistically significant in adjusted analyses. The observed differences began within the first year after diagnosis. Household income was not associated with survival.
\end{abstract}

Conclusions: Also in Sweden, with universal health care, there are indications of inequalities in survival after childhood cancer diagnosis. Further studies are needed to determine which mechanisms explain the association.

In the past decades, survival from childhood cancer have increased to a great extent in high-income countries (Kaatsch, 2010; Gatta et al, 2014), including Sweden (Gustafsson et al, 2013). Overall 5 -year survival is now around $80 \%$ but differs depending on type of cancer (Kaatsch, 2010; Gustafsson et al, 2013; Pritchard-Jones et al, 2013; Gatta et al, 2014), and some studies indicate that survival varies across levels of parental socioeconomic status (SES). A recent systematic review found that even in high-income countries children from lower socioeconomic groups have poorer survival after a cancer diagnosis (Gupta et al, 2014).

SES is a wide concept including both economic and social resources and capabilities (Quaglia et al, 2013). As such, it might have an effect on cancer survival through several mechanisms: related to the stage at diagnosis, treatment, and contacts with health care (Quaglia et al, 2013; Gupta et al, 2014). In Sweden, health care is free of charge and offered to all inhabitants, and it is regulated by the Health and Medical Service Act that those in greatest need of care should be prioritised (The Health and Medical
Service Act, 1982:763). In addition, standardised treatment protocols are available within childhood oncology. Within this context, one would expect indicators related to resources to have less impact on survival than indicators related to ability and knowledge, a hypothesis that was recently confirmed in a study from Norway (Syse et al, 2012). A study from the United Kingdom reported socioeconomic differences in survival from acute lymphoblastic leukaemia (ALL) that became apparent primarily from the time when hospital treatment ended and continued therapy was administered in the child's home (Lightfoot et al, 2012). The authors discuss treatment adherence as a potential explanation.

Several different indicators of SES have been measured in earlier studies, and as they capture different aspects, it is important to study them in conjunction in order to better understand the underlying mechanisms. This could help targeting areas where potential improvements can be made. Our aim was to study whether survival from childhood cancer varies according to parental education and income at the time of the child's diagnosis.

*Correspondence: H Mogensen; E-mail: hanna.mogensen@ki.se

Received 13 July 2015; revised 30 November 2015; accepted 1 December 2015; published online 5 January 2016

(c) 2016 Cancer Research UK. All rights reserved 0007-0920/16 


\section{MATERIAL AND METHODS}

This is a nationwide, population-based cohort study performed by linking information from Swedish national registers using the unique personal identification number assigned to all Swedish residents. We identified all children aged 0-14 years with a first primary diagnosis of cancer registered in the Swedish Cancer Register between 1991 and 2010, a total of 5331 children. Reporting to the Swedish Cancer Register is mandatory since 1958, and all diagnoses are coded according to the International Classification of Diseases (ICD) (The National Board of Health and Welfare, 2015). Tumours have consistently been coded according to the ICD-7 version (for all tumours except leukaemia) and the ICD-8 version (for leukaemia) over the entire time period that the Swedish Cancer Register has been operating. When newer ICD versions have been introduced, they were always complemented with coding from earlier versions (The National Board of Health and Welfare, 2015). In this study, we used the coding from ICD-7, and for leukaemia ICD-8, because only these ICD versions were available for the whole study population. The Swedish Cancer Register also includes benign tumours and tumours of uncertain behaviour.

The outcome of interest was overall survival. The children were followed for a maximum 10 years from the date of their first cancer diagnosis until death, emigration (that was not followed by immigration within the follow-up period), or the end of follow-up 31 December 2011, whichever occurred first. Information about deaths was available from the Cause of Death Register and migrations from the Total Population Register.

From the Total Population Register, we also identified the child's household members. In this register, a household is defined as individuals living at the same residence who are connected through marriage, partner registration, co-habitation with common children, or parenthood (including biological/adoptive/foster parents and other guardians), and all household members are assigned a code describing their role in the household (Statistics Sweden, 2011). This code was used to define the children's social family, including parents and the number of siblings aged $<18$ years living in the household. The register information is updated annually and the information for the year before the child's cancer diagnosis was used. However, many children diagnosed with cancer during their first year of life were not yet born the calendar year before their diagnosis and the household linkage could not be performed. Therefore, we excluded all children diagnosed within their first year of life from the analysis $(n=545)$.

Parental educational level and household income were used as indicators of parental SES. For each child, information about the attained educational level of one parent (mother if available) and the household disposable income was obtained from the Longitudinal Integration Database for Health Insurance and Labour Market Studies (Swedish acronym LISA) (Statistics Sweden, 2011). We decided a priori to primarily focus on maternal educational level because it is comparable to what earlier studies have used (Syse et al, 2012; Erdmann et al, 2014). Mothers are also the ones who receive the majority of the parental benefits from the government in Sweden (The Swedish Social Insurance Agency, 2011, 2015). Education was categorised as compulsory (9 years) or less, upper-secondary (additional secondary school, up to 3 years) and postsecondary education. The household disposable income represents the sum of all household incomes after taxes and any monetary social benefits and was categorised into quartiles according to the annual distribution among the included children, referred to as Q1 (lowest income), Q2, Q3, and Q4 (highest income). To minimise the impact from the child's disease on the socioeconomic indicators, information regarding the calendar year before the cancer diagnosis was used.
To assess how often the parents defined from the household differed from the biological parents, information regarding the biological parents was obtained from the Multi-Generation register (Statistics Sweden, 2010).

Additional information on characteristics of the child and parents was obtained from the Swedish Cancer Register and the Total Population Register.

Statistical analyses. Kaplan-Meier curves were used to visualise the crude survival proportion of children in the different strata of parental SES. The effects of parental educational level and household income on survival were estimated as hazard ratios (HRs) and 95\% confidence intervals (CIs) using Cox regression models. Crude models and models adjusted for sex, age at diagnosis (1-4, 5-9, 10-14 years), year of diagnosis (1991-1995, 1996-2000, 2001-2005, 2006-2010), and six health care regions, that is, the geographical region where the child was living at the time of diagnosis, were estimated. In addition, parental age (the age of the parent for whom the educational level was determined, 5 -year categories), the number of siblings $(0,1, \leqslant 2)$, the number of parents born outside of Sweden $(0,1,2)$ and the number of parents in household $(1,2)$ were additionally included in fully adjusted models. The adjustment variables were selected $a$ priori to assess whether these factors could explain a potential association between parental SES and childhood cancer survival. To evaluate whether the effect of parental educational level on survival within the first year after diagnosis was different from the effect on survival during year 1-10 after diagnosis, a Cox regression model with timevarying coefficients was fitted. Schoenfeld residuals were used to test the proportional hazards assumption, and the assumption holds for all the models.

Stratified analyses were conducted for the most common diagnostic groups; leukaemia (ICD-8: 204-207), tumours of the nervous system (ICD-7: 193), and lymphoma (ICD-7: 200-202). Additionally, analyses restricted to ALL (ICD-8: 204.0) and brain tumours (ICD-7: 193.0) were conducted.

SAS 9.3 (SAS Institute, Cary, NC, USA) was used for the data linkage and the analyses were performed in STATA 13 (StataCorp LP, College Station, TX, USA).

Ethical considerations. This study was approved by the Regional Ethical Review Board in Stockholm.

\section{RESULTS}

Out of the 4786 children diagnosed with cancer, 63 could not be linked to at least one parent and were therefore excluded. Characteristics of the remaining 4723 children in the study population are shown in Table 1 . The 63 excluded children had similar distribution of sex, and mean age and year at diagnosis, as well as 5- and 10-year survival as the included children. In total among the 4723 children, 847 deaths occurred during 32541 person-years. Thirty-two percent of the children, $n=1492$, were diagnosed with leukaemia, among whom 1130 (76\%) had ALL. Among the 1398 children (30\%) with a tumour of the nervous system, 1169 (84\%) were diagnosed with brain tumours. Eleven percent of the children had lymphoma $(n=528)$. Almost $80 \%$ of the children in this study (79\%) lived with both their biological parents; $96 \%$ lived with their biological mother and $82 \%$ lived with their biological father. Information about parental educational level was missing for 23 children (0\%), these children were excluded from all analyses. Parental educational level was based on information from the mothers in 4548 children (97\%).

Figure 1 visualises a pattern of lower survival in children to parents with lower education. Among all diagnoses combined, 91\% of the children to parents with compulsory or less education survived the first year after the diagnosis, while the corresponding 
Table 1. Characteristics of children diagnosed with cancer at age 1-14 years, during the years 1991-2010

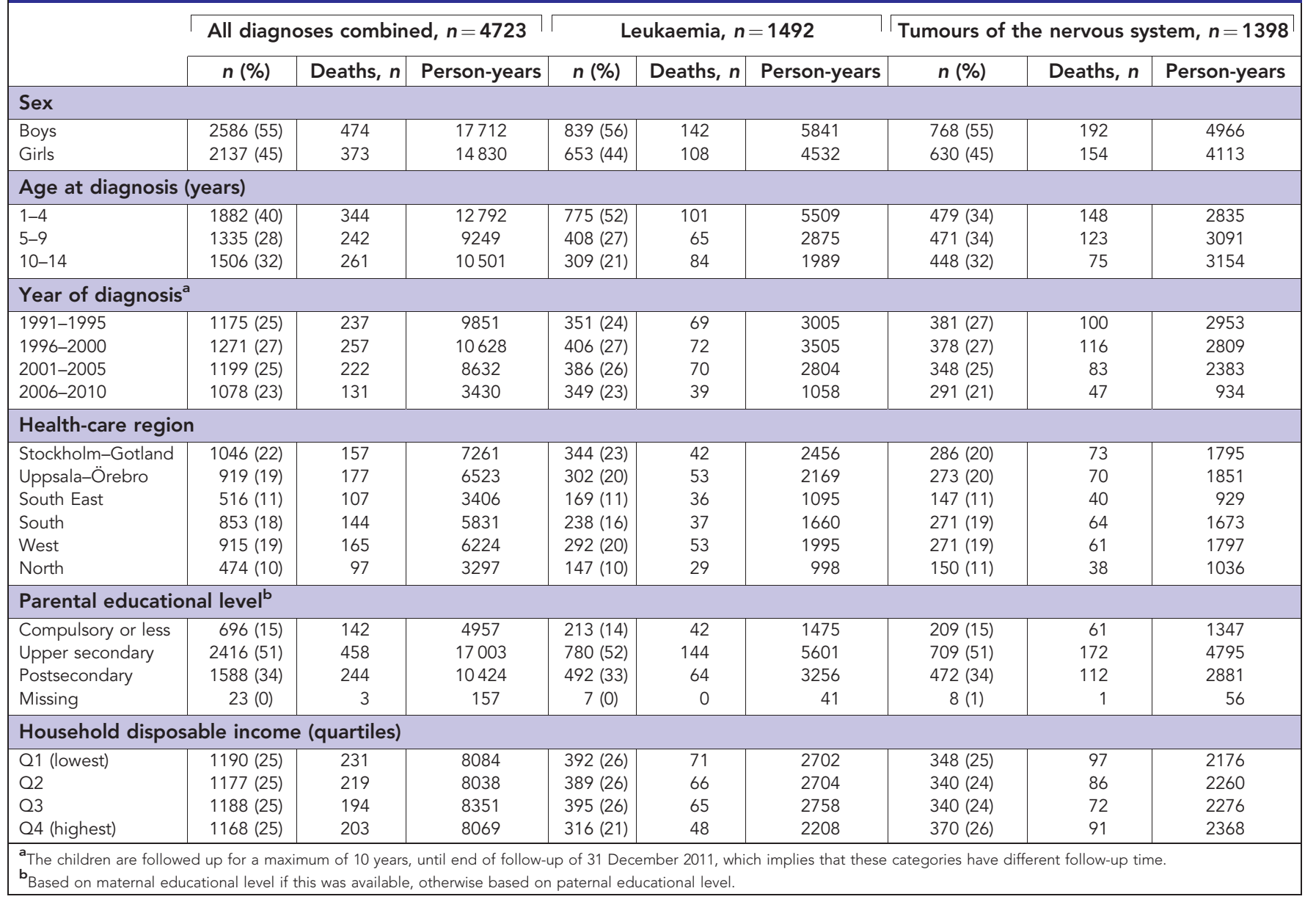

figures for children to parents with upper-secondary education was $93 \%$, and for postsecondary education $94 \%$. Five-year survival, all diagnoses combined, were $81 \%$ (compulsory or less), $82 \%$ (upper secondary) and $85 \%$ (postsecondary), and the corresponding numbers for 10-year survival were 78,80 , and $83 \%$, respectively. No consistent patterns were observed for household income (not shown).

The poorer survival after cancer diagnosis among children to parents in the two lower educational groups was also observed in the Cox regression models (Table 2). The crude HRs were 1.32 (95\% CI 1.07-1.62) and 1.21 (95\% CI 1.04-1.41) for compulsory or less and upper-secondary education, respectively. The estimates changed only slightly when adjusting for other covariates both in the adjusted (Table 2) and fully adjusted model (Supplementary Table S1). Household income did not affect survival (Table 2). There was no strong correlation between parental educational level and household income; the Spearman's rho for all diagnoses combined was 0.26 .

For leukaemia, the effect of parental educational level on children's survival was broadly similar to that observed for all diagnoses combined (Table 3 ), although not statistically significant in the adjusted model (compulsory or less: HR 1.39, 95\% CI $0.93-$ 2.08; upper secondary: HR 1.28, 95\% CI 0.95-1.74). For children with ALL, the HR was close to unity among children whose parents had compulsory or less education, whereas a slightly elevated, although not statistically significant, HR was observed among children whose parents had upper-secondary education. For children with tumours of the nervous system, elevated HRs were found for the lowest parental education compared with the highest, although not statistically significant. Somewhat stronger associations were seen when restricting the analysis to children with brain tumours, but also these were not statistically significant. Adjustments for additional covariates in the fully adjusted models had small impact on the effect estimates (Supplementary Table S2).

Among the 523 analysed cases of lymphoma, no statistically significant associations between survival and parental educational level or household income were found (not shown). In the adjusted model the HR (95\%CI) for compulsory or less education was 1.13 (0.46-2.77) and for upper-secondary education 1.35 (0.69-2.64), compared with postsecondary. Adjusted HRs (95\% CI) for household income were Q1, $1.37(0.62-3.02)$; Q2, $1.36(0.63-$ 2.94); and Q3, 0.67 (0.28-1.56), all compared with Q4.

There was no statistically significant difference in the effect of parental educational level on survival when comparing the first year after diagnosis with the following 9 years (Table 4). Moreover, the poorer survival in the group of children whose parents had compulsory or less education was seen already in the first year. However, the point estimates indicated a different pattern among the two main diagnostic groups. Although not statistically significant, the results give an indication that, among cases of leukaemia, the relative differences continue after the first year, while for tumours of the nervous system the potential survival disadvantage for the group with low educated parents seems more pronounced within the first year after diagnosis.

\section{DISCUSSION}

In this study, we found that children whose parents have lower education experienced poorer cancer survival compared with children of parents with higher education. The association was statistically significant for all cancer diagnoses combined, and 

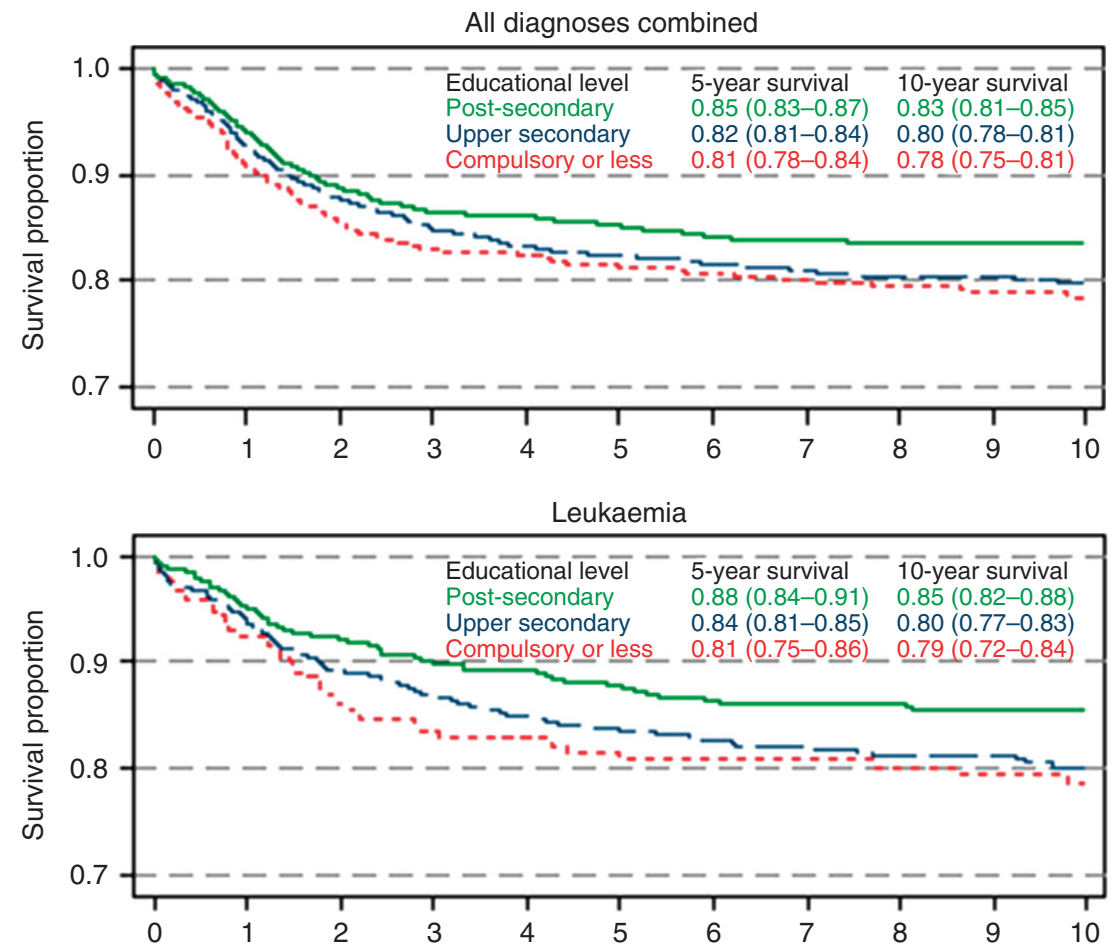

Tumours of the nervous system

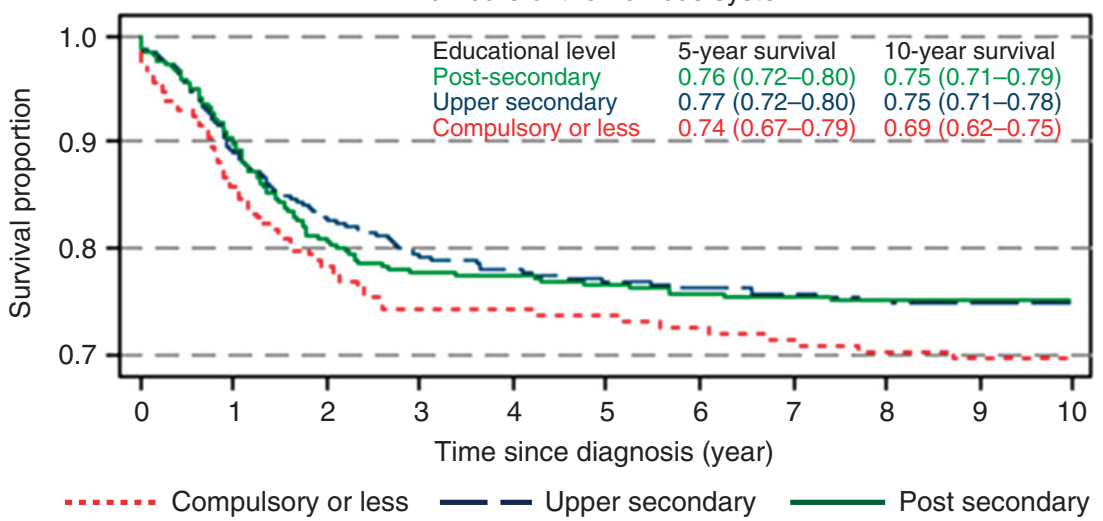

Figure 1. Overall survival after childhood cancer diagnosis according to parental educational level, estimated with the Kaplan-Meier method, and 5- and 10-year survival proportion with $95 \% \mathrm{Cl}$.

similar effects, although not statistically significant, were found for leukaemia and nervous system tumours. Household income was not associated with survival. Moreover, we also found that the survival differences were present already during the first year after diagnosis.

Findings from earlier studies assessing the role of SES on childhood cancer survival from high-income countries similar to Sweden have shown inconsistent results. The majority of studies are confined to leukaemia (Gupta et al, 2014). Two studies from the United Kingdom found poorer survival in leukaemia (Njoku et al, 2013) and ALL (Lightfoot et al, 2012; Njoku et al, 2013) for children to parents with lower SES, measured by paternal occupational social class at birth (Lightfoot et al, 2012; Njoku et al, 2013) and area-based deprivation (Lightfoot et al, 2012), whereas a recent German study of ALL reported no associations (Erdmann et al, 2014). Few studies have investigated the role of SES in survival from childhood cancer diagnoses other than leukaemia. Two studies of survival among children with tumours in the nervous system reported no association with parental SES
(Tseng et al, 2006; Walsh et al, 2011), contrary to our results. A Canadian study observed no socioeconomic differences in survival from childhood lymphoma (Darmawikarta et al, 2013), similar to our findings.

Explanations of inconsistencies between studies may be related to the use of different SES indicators and by differences in the social structure, for example, how the health care is organised. Both the SES indicators and the social structure underlying this study are similar to a Norwegian study where children to mothers with higher educational level had better survival in childhood cancer, while parental earnings had no effect on survival (Syse et al, 2012), which are in line with our findings.

To be able to conduct interventions to raise the level of survival among children to parents with lower SES, the intermediate mechanisms must be identified (Quaglia et al, 2013; Gupta et al, 2014). This study conveys an important message showing that, also in the Swedish context with universal health care, socioeconomic differences in childhood cancer survival seem to be present. Similar differences are known among Swedish adults 
Table 4. Mortality after childhood cancer diagnosis according to parental educational level; comparison of the effect during the first year after diagnosis and the effect during the following 9 years (conditioned on surviving the first year)

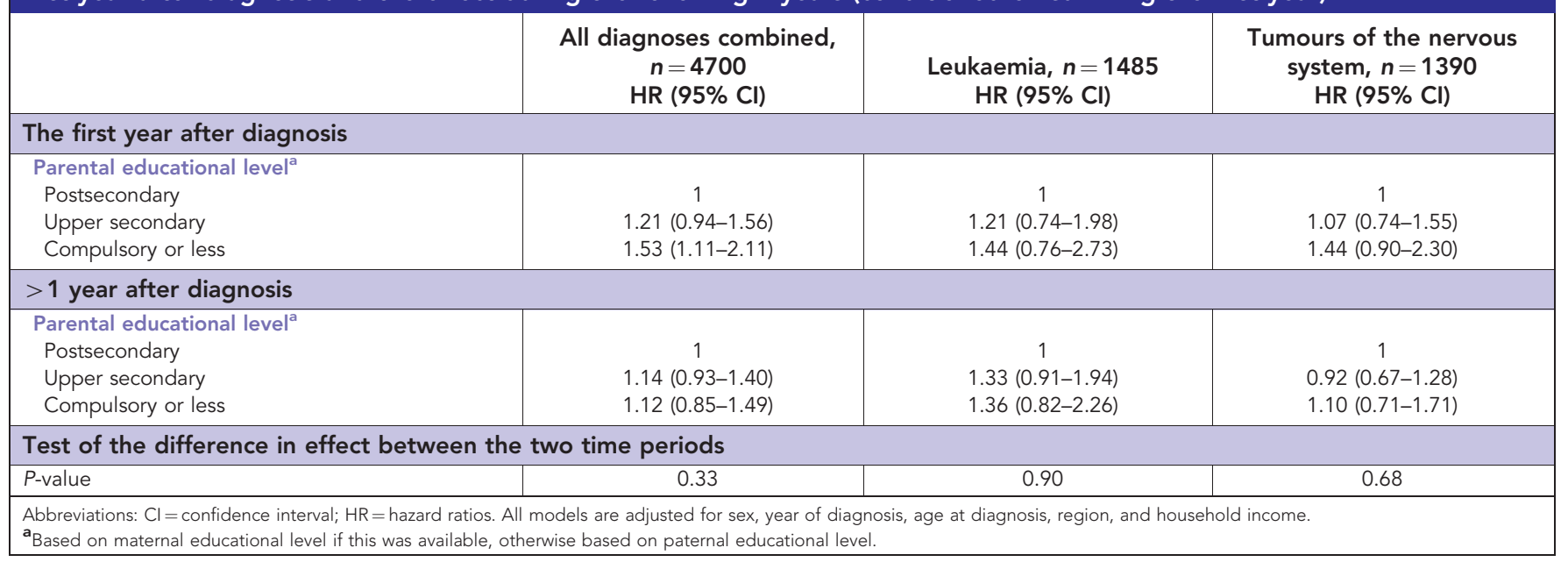

implies very precise calculations of the follow-up time for each child and accurate classification of parental SES as the information is individually and objectively measured. We believe it is a strength that the income variable was not solely based on earnings of the parents but also includes social benefits as it reflects the households' actual material resources. Our approach minimises the risk of misclassification of SES. Non-differential misclassification of SES and thereby diluted effect estimates might be a problem in studies using area-based measurements or information from much earlier in the child's life.

Another advantage of the present study is that we used information from the year before the child's diagnosis. Parental SES can be influenced by the severity of the child's disease and using information of SES from later time points can therefore lead to biased associations. For this reason, we restricted our study population to children diagnosed after their first year in life.

We included social parents instead of biological parents to more accurately reflect the SES of the household at the time of the child's diagnosis. About $20 \%$ of the children did not live in the same household as both their biological parents. If we instead had used SES indicators of the biological parents, these children might have been misclassified. However, in Sweden it is only possible to be registered at one household, which is the base from where we defined the parents. Thus, for children to separated parents, who spend time in two households, only one of them is captured.

A limitation in the study is the lack of statistical power that prevented us from analysing more specific diagnostic subgroups, which would have been of interest as both survival and treatment protocols largely differs between different types of cancer. In addition, we cannot rule out chance as a potential explanation for some of our results. However, even though many of our results for different types of childhood cancer did not reach statistical significance, there is a consistent pattern of a social gradient, from parental educational level, that is not negligible.

\section{CONCLUSION}

This study showed that children to parents with lower education experience poorer survival from childhood cancer compared with children of parents with higher education, while household income was not associated with survival. The differences in survival started already within the first year after the diagnosis. These results give an important message that also in Sweden, a country with universal health care, there are indications of inequalities in survival after childhood cancer diagnosis. Further studies are needed to confirm our findings and determine which mechanisms explain the observed association.

\section{ACKNOWLEDGEMENTS}

This study was supported by funding from the Swedish Research Council for Health, Working Life and Welfare contract no. 2013-1072.

\section{CONFLICT OF INTEREST}

The authors declare no conflict of interest.

\section{REFERENCES}

Bhatia S, Landier W, Hageman L, Chen Y, Kim H, Sun CL, Kornegay N, Evans WE, Angiolillo AL, Bostrom B, Casillas J, Lew G, Maloney KW, Mascarenhas L, Ritchey AK, Termuhlen AM, Carroll WL, Wong FL, Relling MV (2015) Systemic exposure to thiopurines and risk of relapse in children with acute lymphoblastic leukemia: a Children's Oncology Group Study. JAMA Oncol 1(3): 287-295.

Bhatia S, Landier W, Hageman L, Kim H, Chen Y, Crews KR, Evans WE, Bostrom B, Casillas J, Dickens DS, Maloney KW, Neglia JP, Ravindranath Y, Ritchey AK, Wong FL, Relling MV (2014) 6MP adherence in a multiracial cohort of children with acute lymphoblastic leukemia: a Children's Oncology Group study. Blood 124(15): 2345-2353.

Cavalli-Bjorkman N, Lambe M, Eaker S, Sandin F, Glimelius B (2011) Differences according to educational level in the management and survival of colorectal cancer in Sweden. Eur J Cancer 47(9): 1398-1406.

Darmawikarta D, Pole JD, Gupta S, Nathan PC, Greenberg M (2013) The association between socioeconomic status and survival among children with Hodgkin and non-Hodgkin lymphomas in a universal health care system. Pediatr Blood Cancer 60(7): 1171-1177.

Erdmann F, Kaatsch P, Zeeb H, Roman E, Lightfoot T, Schuz J (2014) Survival from childhood acute lymphoblastic leukaemia in West Germany: does socio-demographic background matter? Eur J Cancer 50(7): 1345-1353.

Eriksson H, Lyth J, Mansson-Brahme E, Frohm-Nilsson M, Ingvar C, Lindholm C, Naredi P, Stierner U, Wagenius G, Carstensen J, Hansson J (2013) Low level of education is associated with later stage at diagnosis and reduced survival in cutaneous malignant melanoma: a nationwide population-based study in Sweden. Eur J Cancer 49(12): 2705-2716. 
Gatta G, Botta L, Rossi S, Aareleid T, Bielska-Lasota M, Clavel J, Dimitrova N, Jakab Z, Kaatsch P, Lacour B, Mallone S, Marcos-Gragera R, Minicozzi P, Sanchez-Perez MJ, Sant M, Santaquilani M, Stiller C, Tavilla A, Trama A, Visser O, Peris-Bonet R (2014) Childhood cancer survival in Europe 1999-2007: results of EUROCARE-5-a population-based study. Lancet Oncol 15(1): 35-47.

Gupta S, Wilejto M, Pole JD, Guttmann A, Sung L (2014) Low socioeconomic status is associated with worse survival in children with cancer: a systematic review. PLoS One 9(2): e89482.

Gustafsson G, Kogner P, Heyman M (eds) (2013) Childhood Cancer Incidence and Survival in Sweden 1984-2010, Report 2013, From the Swedish Childhood Cancer Registry. Available from http://www.cceg.ki.se/ documents/ChildhoodCancerIncidenceandSurvivalinSweden1984_2010.pdf.

Kaatsch P (2010) Epidemiology of childhood cancer. Cancer Treat Rev 36(4): 277-285.

Lagerlund M, Bellocco R, Karlsson P, Tejler G, Lambe M (2005) Socio-economic factors and breast cancer survival-a population-based cohort study (Sweden). Cancer Causes Control 16(4): 419-430.

Lightfoot TJ, Johnston WT, Simpson J, Smith AG, Ansell P, Crouch S, Roman E, Kinsey SE (2012) Survival from childhood acute lymphoblastic leukaemia: the impact of social inequality in the United Kingdom. Eur J Cancer 48(2): 263-269.

Mancini J, Simeoni MC, Parola N, Clement A, Vey N, Sirvent N, Michel G, Auquier P (2012) Adherence to leukemia maintenance therapy: a comparative study among children, adolescents, and adults. Pediatr Hematol Oncol 29(5): 428-439.

Njoku K, Basta N, Mann KD, McNally RJ, Pearce MS (2013) Socioeconomic variation in survival from childhood leukaemia in northern England, 1968-2010. Br J Cancer 108(11): 2339-2345.

Pritchard-Jones K, Pieters R, Reaman GH, Hjorth L, Downie P, Calaminus G, Naafs-Wilstra MC, Steliarova-Foucher E (2013) Sustaining innovation and improvement in the treatment of childhood cancer: lessons from high-income countries. Lancet Oncol 14(3): e95-e103.

Quaglia A, Lillini R, Mamo C, Ivaldi E, Vercelli M. Group SW (2013) Socio-economic inequalities: a review of methodological issues and the relationships with cancer survival. Crit Rev Oncol Hematol 85(3): 266-277.

Statistics Sweden (2010) Background Facts, Population and Welfare Statistics 2010:3, Multigeneration register 2009. A description of contents and quality (ISSN 1654-4331 (online)). Available from http://www.scb.se/ statistik/_publikationer/BE9999_2009A01_BR_BE96BR1003.pdf.

Statistics Sweden (2011) Background Facts, Labour and Education Statistics 2011:4, Integrated database for labour market research (ISSN 1654-465X (online)). Available from http://www.scb.se/statistik/ _publikationer/AM9901_1990I09_BR_AM76BR1104.pdf.

Syse A, Lyngstad TH, Kravdal O (2012) Is mortality after childhood cancer dependent on social or economic resources of parents? A populationbased study. Int J Cancer 130(8): 1870-1878.

The Health and Medical Service Act (1982:763) (English translation). In Swedish: Hälso- och sjukvårdslag (1982:763). Available from http:// www.riksdagen.se/sv/Dokument-Lagar/Lagar/Svenskforfattningssamling/ Halso-och-sjukvardslag-1982_sfs-1982-763/.

The National Board of Health and Welfare (2015) Kodning i Cancerregistret, Handledning 2015 (2015-1-30). Available from http://www.socialstyrelsen.se/ Lists/Artikelkatalog/Attachments/19675/2015-1-30.pdf.

The Swedish Social Insurance Agency (2011) Socialförsäkringsrapport 2011:13 (Social Insurance Report) - Föräldrapenning- Båda föräldrarnas försäkring? (ISSN: 1654-8574). Available from https://www.forsakringskassan.se/ wps/wcm/connect/c18218dc-3d5f-4721-b1dc-a800f7e9d713/ socialforsakringsrapport_2011_13.pdf?MOD=AJPERES.

The Swedish Social Insurance Agency (2015) Socialförsäkringen i siffror 2015 (ISSN: 1650-2248). Available from https://www.forsakringskassan.se/ wps/wcm/connect/7409a3e3-ffbd-498d-a35d-1f0afceebfad/ socialforsakringen_i_siffror_2015.pdf?MOD=AJPERES.

Tseng MY, Tseng JH, Merchant E (2006) Comparison of effects of socioeconomic and geographic variations on survival for adults and children with glioma. J Neurosurg 105(4 Suppl): 297-305.

Walsh PM, Byrne J, Capra M, Comber H (2011) Childhood cancer survival in Ireland: temporal, regional and deprivation-related patterns. Eur J Cancer 47(12): 1852-1862.

This work is published under the standard license to publish agreement. After 12 months the work will become freely available and the license terms will switch to a Creative Commons AttributionNonCommercial-Share Alike 4.0 Unported License.

Supplementary Information accompanies this paper on British Journal of Cancer website (http://www.nature.com/bjc) 